\title{
Workers of Acromyrmex echinatior leafcutter ants police worker-laid eggs, but not reproductive workers
}

\author{
Michiel B. Dijkstra*, Jelle S. van Zweden ${ }^{1}$, Maria Dirchsen ${ }^{2}$, Jacobus J. Boomsma ${ }^{2}$ \\ Department of Biology, Centre for Social Evolution
}

\section{A R T I C L E I N F O}

\section{Article history:}

Received 30 December 2009

Initial acceptance 22 February 2010

Final acceptance 4 June 2010

Available online 21 July 2010

MS. number: 09-00817R

\section{Keywords:}

Acromyrmex echinatior

cost of worker reproduction

leafcutter ant

multiple queen mating

reproductive self-restraint

worker policing

\begin{abstract}
Nonreproductive workers of many eusocial Hymenoptera 'police' the colony, that is, they attack reproductive sister workers or destroy their eggs (unfertilized; developing into haploid males). Several ultimate causes of policing have been proposed, including (1) an increase in colony productivity, applicable if reproductive workers work less, or (2) an increase in worker-to-male relatedness, applicable if withincolony relatedness is low. To explain the distribution of policing across taxa, the explanatory power of these and other potential ultimate causes should be assessed separately. One of the few species for which this can be done is the leafcutter ant Acromyrmex echinatior. We previously demonstrated that colony productivity incentives (and sex ratio incentives) are minimal here, while relatedness incentives are strong because queens are highly multiply mated. Overcoming technical difficulties peculiar to leafcutter ants, we introduced reproductive versus nonreproductive workers and batches of queen-laid versus worker-laid eggs into experimental colony fragments and observed their fate. Our main finding was that workers policed by selectively destroying worker-laid eggs, but without attacking reproductive workers. We infer that relatedness incentives are the most likely ultimate cause of the evolutionary maintenance of worker-egg policing in A. echinatior.
\end{abstract}

(c) 2010 The Association for the Study of Animal Behaviour. Published by Elsevier Ltd. All rights reserved.
Workers of eusocial Hymenoptera (wasps, bees, ants) are always females. They typically have ovaries, but unlike queens they lack genitalia and a spermatheca, so they cannot mate. Any worker-laid eggs will remain unfertilized and can develop into fertile haploid males because of the hymenopteran haplodiploid sex determination system (Choe 1988; Bourke 1988; for exceptions see Pirk et al. 2003; Hartmann et al. 2004). As in nonsocial organisms, the number of dispersing virgin queens (queen daughters) and males (queen and/or worker sons) that a colony can produce is resourcelimited. It is thus important for workers, which nurse the brood, to raise selectively those sexuals that yield the greatest fitness return.

The direct fitness benefits of egg laying to workers are potentially high, as workers are at least one-third more related to their sons (average life-for-life relatedness coefficient $(\bar{r}=0.50)$ than to any other males that could be produced in the colony $(\bar{r} \leq 0.375)$. However, it has been shown that in many species, mainly or

\footnotetext{
* Correspondence and present address: M. B. Dijkstra, Department of Ecology and Evolution, University of Lausanne, Quartier Sorge, 'Le Biophore', CH-1015 Lausanne, Switzerland.

E-mail address: Michielbendert.Dijkstra@unil.ch (M.B. Dijkstra).

1 J. S. van Zweden is now at the Laboratory of Apiculture \& Social Insects, Department of Biological \& Environmental Sciences, University of Sussex, Brighton BN1 9QG, East Sussex, U.K.

2 M. Dirchsen and J. J. Boomsma are at the Department of Biology, Centre for Social Evolution, Universitetsparken 15, DK-2100 Copenhagen, Denmark.
}

exclusively queen sons are produced in the queen's presence (reviewed in Hammond \& Keller 2004; Wenseleers \& Ratnieks 2006a; Ratnieks \& Wenseleers 2008), implying that few workers ever have sons.

An important and widespread proximate cause of the predominance of queen sons is self-restraint, that is, workers refraining from laying reproductive eggs except after losing their queen. However, self-restraint can only be adaptive if the average number of sons obtained by a reproductive worker is approximately zero because of interference by sister workers or the queen (e.g. Ratnieks 1988; Wenseleers et al. 2004a, b; Helanterä 2007; Wenseleers \& Ratnieks 2006b). For example, self-restraining workers can attack reproductive workers to prevent them from laying (hereafter: 'worker-worker policing'), selectively destroy worker-laid eggs ('worker-egg policing') or 'seasonally suppress' all sexual brood, that is, only rear virgin queens and males in the weeks preceding the mating season or after irreversible queen loss (Dijkstra \& Boomsma 2007). A long evolutionary history of worker self-restraint could lead to the evolutionary regression (see Jeffery 2005; Protas et al. 2007) of traits regulating the ontogeny and physiology of worker ovaries (Beekman \& Oldroyd 2005; Helanterä et al. 2006), which may explain the faulty expression of key developmental genes in worker-produced oocytes, which causes these eggs to die inside the ovary or during embryonic development ('reproductive constraint', Khila \& Abouheif 2008). 
Since its first discovery in the European honeybee, Apis mellifera (Ratnieks 1988; Ratnieks \& Visscher 1989) worker policing has been demonstrated in many singly and multiply mated species of bees, wasps and ants (reviewed in Ratnieks et al. 2006; Wenseleers \& Ratnieks 2006a, b; Ratnieks \& Wenseleers 2008). A greater relatedness of workers to brothers (queen sons) than to nephews (worker sons) is thought to be an important ultimate cause of worker policing (e.g. Woyciechowski \& Łomnicki 1987; Ratnieks 1988; Pamilo 1991; Ratnieks \& Wenseleers 2008). Between-colony differences in 'relatedness asymmetry', that is, the ratio of the average relatedness of workers to brothers versus nephews, are currently the only known explanation for the facultative worker policing of worker-laid eggs in the wasp Dolichovespula saxonica (Foster \& Ratnieks 2000). Relatedness asymmetry is also a sufficient explanation for: (1) the absence of worker policing in some singly mated societies, with average lifefor-life relatedness of workers to worker sons of $\bar{r} \approx 0.375$ (e.g. the ant Temnothorax unifasciatus, in which self-restraining workers do not police: Stroeymeyt et al. 2007; many stingless bee species: e.g. Alves et al. 2009; reviewed in Tóth et al. 2004); (2) the presence of worker policing in the ants Formica fusca and Pachycondyla inversa, which have multiple queens per colony $(\bar{r} \approx 0.25$; D'Ettorre et al. 2004; Helanterä \& Sundström 2005, 2007; Kellner et al. 2007; van Zweden et al. 2007); and (3) the prevalence of worker policing in the multiply mated honeybees and vespine wasps $(\bar{r}<0.25$; Ratnieks et al. 2006; Wenseleers \& Ratnieks 2006a, b).

It has long been recognized that worker policing may also be selectively favoured when policing helps to maximize the total production of virgin queens and males by increasing colony efficiency (Cole 1986; Ratnieks 1988; Hartmann \& Heinze 2003; Wenseleers et al. 2004a, b; Hartmann et al. 2004; Helanterä 2006; Dijkstra \& Boomsma 2007; Ratnieks \& Wenseleers 2008). Growing eggs and egg laying are expected to reduce a worker's output of work for the colony because of time budget and energy constraints (Ratnieks 1988). Efficiency incentives alone might have selected for worker policing in societies in which relatedness asymmetry disfavours policing, for example the singly mated wasps Vespa crabro and Polistes chinensis antennalis (Foster et al. 2002; Saigo \& Tsuchida 2004). Unfortunately, disentangling potential relatedness incentives, efficiency incentives and other potential incentives for worker policing in individual taxa is difficult: different types of incentives may be mutually reinforcing, while the colony-level cost of workers laying eggs can rarely be quantified and are unlikely to be constant across taxa. So far, three studies have tried to estimate the cost of worker reproduction in ants by correlating the presence/absence of a high proportion of reproductive workers with a measure of colonylevel work output: (1) Cole (1986) found a ca. $14 \%$ cost measured in time spent on brood care in Leptothorax allardycei; (2) Gobin et al. (2003) found a ca. 90\% metabolic cost in Pachycondyla obscuricornis; and (3) Dijkstra \& Boomsma (2007) found a $<2 \%$ cost measured in mutualistic fungus garden volume in Acromyrmex leafcutter ants. For taxa for which estimates of the colony-level efficiency cost of worker reproduction are lacking, the relative importance of efficiency versus relatedness incentives for the evolution of worker policing can only be assessed by two methods: (1) correlating the presence/absence of worker policing with the species-specific average within-colony relatedness across a large comparative data set, while assuming that there is random variation in efficiency incentives across species (Wenseleers \& Ratnieks 2006b; Helanterä 2007); or (2) investigating whether a mechanism for worker policing exists in parthenogenetic species in which relatedness benefits for policing are absent (Hartmann \& Heinze 2003; Pirk et al. 2003; Hartmann et al. 2004).

The aim of the present study was to test for the existence of a worker policing mechanism in the Panamanian leafcutter ant Acromyrmex echinatior. We estimated that the cumulative colony-level cost of numerous laying workers is negligible $(<2 \%)$ as long as worker sons (and queen-derived virgin queens and males) are 'seasonally suppressed' after the earliest larval instars (Dijkstra \& Boomsma 2007). However, worker policing is predicted to be selectively favoured in A. echinatior because queens are always highly multiply mated (Sumner et al. 2004). Our study of a species in which there are strong relatedness incentives but negligible efficiency incentives for worker policing therefore provides an interesting mirror image of previous studies of worker policing in parthenogenetic taxa, where the opposite combination of incentives applies (Hartmann \& Heinze 2003; Pirk et al. 2003; Hartmann et al. 2004). Experimental tests for worker policing are more difficult in leafcutter ants than in other social insects because the presence of the mutualistic fungus gardens makes direct observations on egg laying, aggression and policing impossible in mature colonies. To circumvent this problem, which is peculiar to fungus-growing ants (which include the leafcutter ants), we developed new methods that differ from those in previously published studies on worker policing.

\section{METHODS}

\section{Study Species}

The experimental colonies were collected between 2001 and 2005 in Gamboa, Panama and transported to Denmark, where they were kept under controlled conditions (see Dijkstra et al. 2005; Dijkstra \& Boomsma 2008 for details about collection and maintenance). Reproductive colonies of $A$. echinatior in Panama contain between ca. 500 and ca. 40000 workers (median: ca. 7000; see Appendix) and raise $0-950$ males per reproductive season (median $=70$; mean $\pm \mathrm{SD}=159 \pm 222 ; N=45$ colonies: Dijkstra \& Boomsma 2008). In the absence of policing by workers or queens, workers would be expected to produce ca. $59 \%$ of the males in the population, assuming that $1 \%$ of workers are reproductive in the queen's presence (estimate from Dijkstra et al. 2005) and that reproductive workers lay on average a single viable egg (see Appendix for calculation). In reality, field and laboratory colonies produce mainly queen sons as long as the queen is present ( $>97 \%$ of all adult males: M.B. Dijkstra, S.A.O. Armitage, T.R. Gregory \& J.J. Boomsma, unpublished data), although worker sons are commonly raised in orphaned laboratory colonies (Dijkstra \& Boomsma 2007).

\section{General Methods}

The leafcutter ants' obligate association with a mutualistic fungus (reviewed in Currie 2001) has enabled us in a previous study to approximate colony productivity and the cost of worker laying in A. echinatior by measuring the volume of the fungus gardens (Dijkstra \& Boomsma 2007). However, the presence of fungus gardens also makes it impossible to observe policing directly. We therefore performed all experiments on small colony fragments in the laboratory. These never contained a queen, but we assumed that the workers in them behaved as 'queenright' workers (i.e. workers in the presence of their queen, and thus continuing self-restraint and expression of any worker policing behaviour) for 3 days (see Endler et al. 2004 for a similar study making the same assumption). This assumption is likely to be valid, given that ovarian dissections have shown that $A$. echinatior workers do not become reproductive until $\geq 2-3$ weeks after queen loss (Dijkstra \& Boomsma 2007), and that worker-laid eggs are rarely found in orphaned colonies until 23-4 months after queen loss (M. B. Dijkstra \& J. S. van Zweden, independent personal observations). We wore latex gloves during the experiments and always handled eggs and workers with watchmaker's forceps, which were cleaned by successive rinsing in tap water, 99\% acetone and 95\% ethanol between manipulations. 
Preliminary observations (total $19 \mathrm{~h}$ ) on similar colony fragments in the laboratory have indicated that: (1) A. echinatior queens do not interact with their eggs and depend on the workers to place these among the other brood; (2) workers can remove eggs by chewing on them and/or by dumping them on piles of so-called 'infrabuccal pellets' (waste ejected from the infrabuccal cavity of workers) that are deposited away from fungus gardens (see Little et al. 2003); (3) workers typically find eggs accidentally while grazing on the fungus garden's surface, and ignore eggs that are more than ca. $1 \mathrm{~mm}$ away from their antennae; and (4) queens do not graze on the fungus, suggesting that they lack the opportunity to find and 'queen police' (see Ratnieks 1988) eggs laid by workers or other queens (Dijkstra 2005).

\section{Worker-Worker Policing}

The aim of this experiment was to test whether worker-worker policing occurs, that is, whether self-restraining workers are more aggressive to reproductive than self-restraining worker sisters. We divided in half three queenright, mature laboratory colonies (Ae150, Ae155, Ae209; each consisting of two fungus gardens with a total volume of 1-2 litres and containing a single queen; see Dijkstra \& Boomsma 2007 for details). We subsequently maintained the orphaned and queenright nests as independent colonies until the start of the experiment 49-84 days later (Fig. 1a). We constructed colony fragments that contained eight large workers and 22 small workers, six large worker pupae or final-instar larvae and $3.9 \pm 0.1 \mathrm{mg}$ (range $3.4-4.4 \mathrm{mg}$ ) of fresh fungus, all sampled from the same queenright source colony. We jointly refer to the 30 workers in each colony fragment as 'discriminator workers'. The above ratio of large:small discriminator workers was chosen because this closely corresponds to the mean ratio of 1:3 observed in mature laboratory A. echinatior colonies (M. Poulsen, unpublished data). Discriminator workers were exclusively sampled from workers walking on the surface of the fungus garden to exclude two categories of workers: (1) foragers or waste disposal workers, which rarely interact with the brood and might be less motivated to express policing behaviour; (2) rare workers (1\%) that are reproductive in the queen's presence, mainly found among 'curled up' workers (see below). Each colony fragment was placed in a transparent plastic box $(7.2 \times 5.1 \mathrm{~cm}$ and $4.6 \mathrm{~cm}$ high) with a transparent lid. The upper ca. $2 \mathrm{~cm}$ of the interior walls of the box were painted with Fluon (Asahi Glass Co., Yurakucho, Japan) to prevent the workers from escaping when the box was open. The box was connected by a rubber tube (length $3 \mathrm{~cm}$, internal diameter $0.8 \mathrm{~cm}$ ) to an enclosed arena, in which the discriminator workers could place dead fungus and worker corpses (Fig. 1a). Colony fragments were maintained in a dark climate room (ca. $60 \%$ relative humidity; temperature $25^{\circ} \mathrm{C}$ ) throughout the experiment. We used an average of five (range three to eight) replicate colony fragments per colony, using them for a maximum of 2 days after setting them up. We sampled a single large or small worker from the corresponding orphaned nest (Fig. 1a), preferentially taking workers that were lying curled up in the fungus garden, as we have previously shown that these are most likely to be engaged in laying trophic or reproductive eggs (Dijkstra et al. 2005). We marked each sampled worker on the anterior gaster with white, odourless acrylic paint ('Matt White no. 34', Humbrol Ltd., Marfleet, Hull, U.K.), and deposited her on top of the fungus in the colony fragment (Fig. 1a). We closed the lid and immediately started to observe the interior of the box at 6.4-16× magnification under exclusively red light (to which ants are thought to be relatively insensitive), continuing for $10 \mathrm{~min}$, not including periods when the introduced worker was hidden from view. We scored all instances of known aggressive behaviours in ants (e.g. biting, chasing, fleeing, leg pulling, either by discriminator workers towards introduced workers or vice versa), but not worker-worker antennation as this behaviour is considered to be neutral in A. echinatior (Lambardi et al. 2004). We retrieved the introduced worker and kept her in a $1.5 \mathrm{ml}$ tube for $\leq 6 \mathrm{~h}$ until we dissected her ovaries, following the protocol in Dijkstra et al. (2005). We subsequently scored her as either reproductive (i.e. with at least one opaque, reproductive oocyte in her ovaries) or self-restraining (i.e. without yolky oocytes or with exclusively transparent trophic oocytes). We introduced a total of 120 workers (20 large and 20 small workers per colony), alternating introductions between replicate fragments from the same queenright nest. Note that our set-up precludes any potentially confounding effects of nest odour or observer bias, as reproductive and nonreproductive introduced workers were always sisters to the discriminator workers and had been sampled 'blindly' (i.e. without knowledge about their reproductive status until after the observations) from the same orphaned nest.

\section{Worker-Egg Policing}

The aim of this experiment was to test whether worker-egg policing occurs, that is, whether queenright workers destroy worker-laid eggs more frequently than queen-laid eggs. In $A$. echinatior, workers normally wrap clumps of eggs in envelopes of fungal mycelium, but recently laid eggs may lie scattered inside the fungus garden (Dijkstra et al. 2005). We divided in half six mature laboratory colonies (Ae150, Ae153, Ae155, Ae160, Ae223, Ae226, each consisting of two fungus gardens with a total volume of 1-2 litres and containing a single queen), and maintained the resulting orphaned and queenright nests as separate colonies for $182 \pm 25$ days (mean \pm SE; range 98-231 days) until the start of the experiment (see Dijkstra \& Boomsma 2007; Fig. 1b).

We never compared the behaviour of discriminator workers shown towards eggs laid by their own queen versus eggs laid by sister workers. Such a comparison would have introduced a confounding interaction between difference in nest odour and caste of the egg-layer, which might artificially cause worker-laid eggs to become less acceptable to discriminator workers. This is because sufficient numbers of worker-laid eggs can only be obtained from nests that have been separated from their queen for $\geq 3$ months, while discriminator workers must remain with their queen until the start of the experiment (see above). To keep the effect of differences in nest odour between the nest of origin of discriminator workers and introduced eggs constant and high, we paired each of the six colonies with another colony following a randomized design: one colony of each pair would then donate the queenlaid and worker-laid eggs and the other the discriminator workers (Fig. 1b). In other words, each group of discriminator workers would be offered either exclusively eggs laid by an unrelated queen or exclusively eggs laid by unrelated workers.

For the discriminator nests, we created two identical colony fragments from the queenright nest of each of the six colonies, with the same specifications as in the aggressive policing experiment, but with 12 large and 30 small workers (approximately the typical ratio of large to small workers; see above) and no brood. We examined the fungus in each fragment at 6.4-16× magnification in a petri dish rimmed with moist cotton wool and discarded all eggs (presumably all queen-laid), a procedure that took ca. $2.5 \mathrm{~h}$ per colony fragment. These colony fragments were kept for $24 \mathrm{~h}$ without disturbance before any eggs were introduced. To obtain queen- and worker-laid eggs for introduction, we searched the interior of the fungus garden in the corresponding egg-donating nests (Fig. 1b) for egg clumps and carefully removed the mycelial envelope of eggs with forceps. We exclusively sampled shiny white (ca. $0-4$ days old) reproductive eggs (i.e. nontrophic; see Dijkstra et al. 2005 for details) and took care to sample from at least two egg clumps per nest. We deposited 15 eggs, 
(a)

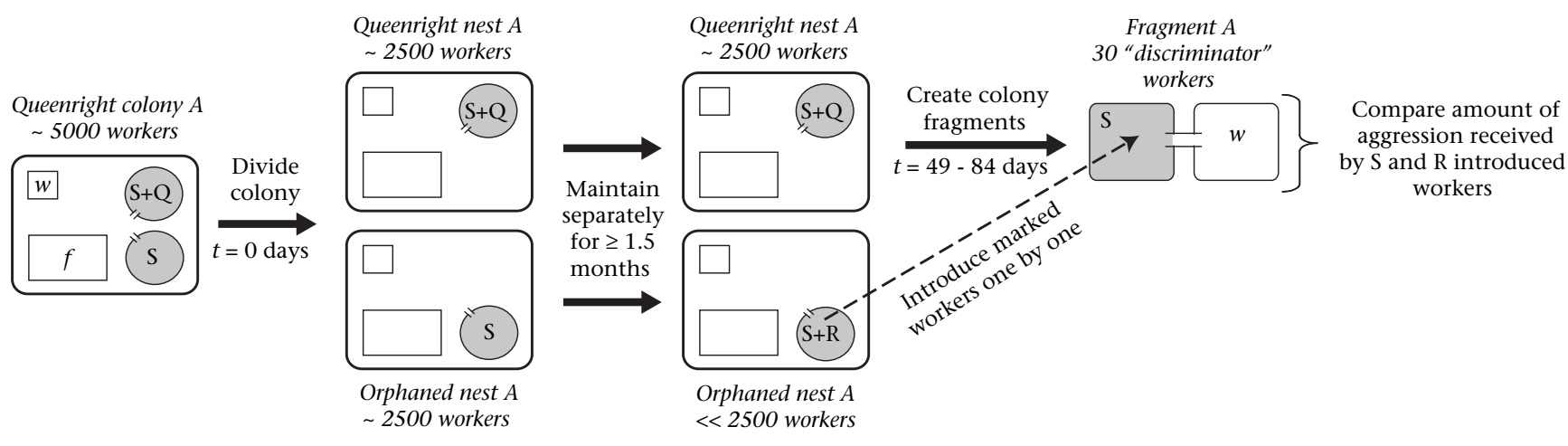

(b)

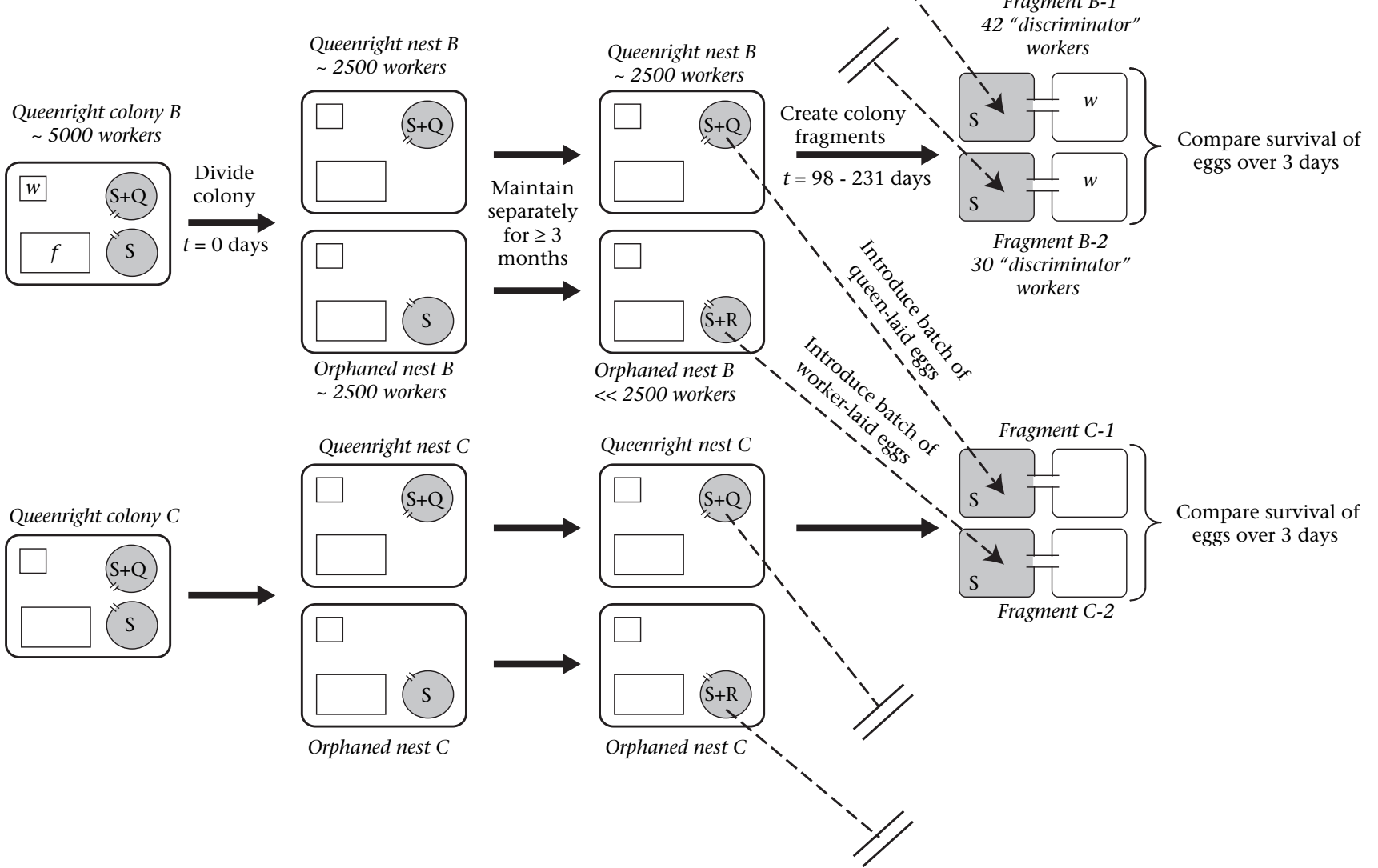

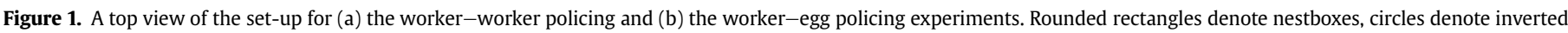



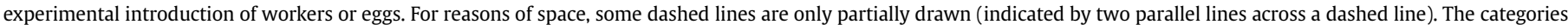

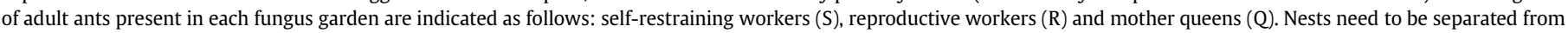

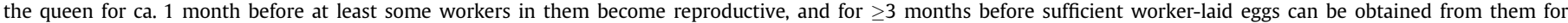
experimental purposes. See text for further details.

either all queen-laid or all worker-laid, and all from the same nest, following the predetermined random pairing, on top of the fungus in each of the 12 receiving colony fragments (Fig. 1b). After having been kept in a dark climate room (ca. $60 \%$ relative humidity; $25^{\circ} \mathrm{C}$ ) for 3 days, the colony fragments were frozen, immersed in $70 \%$ ethanol so that all fungus dissolved, and any eggs remaining were counted. The duration of 3 days per trial was chosen as a compromise between two conflicting requirements: (1) to allow discriminator workers sufficient time to police unwanted eggs; and (2) to minimize the time that discriminator workers were separated from their queen (see above).
We scored undamaged eggs (which would have been lying embedded in the fungus, either freely or as part of an egg clump, or carried by workers) as 'not policed'. All other eggs (i.e. shrivelled or otherwise damaged eggs that were lying discarded in the arena, or eggs that were missing from the original number of 15) were scored as 'policed'.

\section{Statistical Analyses}

We analysed all results by a logistic regression in SAS 9.1.3 (SAS Institute Inc., Cary, NC, U.S.A.) of the relevant response 
variables (e.g. the proportion of introduced workers or nonpoliced eggs that were attacked) on predictor variables with stepwise model simplification until the minimum adequate model was obtained (i.e. with all remaining terms significant at the 0.05 level). All $P$ values for the minimum adequate model in the logistic regressions were obtained after removal of all nonsignificant terms. This procedure was identical to the one described in detail in Dijkstra \& Boomsma (2008). In the worker-egg policing experiment, we corrected for overdispersion by dividing the $\chi^{2}$ values from the likelihood ratio test and by the ratio of the residual deviance and the residual degrees of freedom (see Dijkstra \& Boomsma 2008 for details). Unless otherwise indicated, results are given as mean $\pm \mathrm{SE}, \alpha=0.05$ and $P$ values are two tailed.

\section{RESULTS}

\section{Worker-Worker Policing}

None of the introduced workers were bitten, chased, wounded or killed (see Lambardi et al. 2004) by discriminator workers, nor did they ever behave aggressively themselves. Most (83\%) introduced workers did not receive aggression of any kind. The behaviour of the discriminator workers shown towards the remaining (17\%) introduced workers was striking: they placed their mandibles around an introduced worker's gaster or petiole and lifted her, either putting her down immediately (hereafter: 'lifting'; in $80 \%$ of observed cases) or carrying her around for 1-5 s ('carrying'; $20 \%$ of cases). Introduced workers were sometimes lifted repeatedly (median: once, range 1-4 times) during the $10 \mathrm{~min}$ of observations, not always by the same worker. Lifted or carried workers never resisted but remained motionless and appeared unharmed afterwards.

Ovarian dissections showed that only $25 \%$ and $2 \%$, respectively, of the introduced large and small workers were reproductive, confirming that the majority of workers continue to be selfrestrained after queen loss (Dijkstra \& Boomsma 2007). Because we had preferentially sampled trophic and reproductive egg-laying workers (see Methods), these are overestimates for the percentages of reproductive workers in orphaned colonies. Reproductive workers were not more likely to be lifted $\left(\chi_{1}^{2}=0.53, P=0.466\right)$ or carried $\left(\chi_{1}^{2}=1.44, P=0.229\right)$ than self-restraining workers, indicating that lifting and carrying are unconnected to policing (Table 1 ,
Fig. 2). The interaction between a worker's size (large versus small) and reproductive status (self-restraining versus reproductive) was never significant (lifting: $\chi_{1}^{2}=0.53, P=0.227$; carrying: $\chi_{1}^{2}=1.15$, $P=0.284$ ), showing that self-restraining small workers were equally likely to be lifted or carried as reproductive small workers, and self-restraining large workers were equally likely to be lifted or carried as reproductive large workers (Fig. 2). Small workers were significantly more likely to be lifted than large workers $\left(\chi_{1}^{2}=5.48\right.$, $P=0.019)$ but not more likely to be carried $\left(\chi_{1}^{2}=1.15, P=0.284\right.$; Fig. 2). Lifting was more frequent in some colony fragments than in others $\left(\chi_{2}^{2}=15.76, P=0.004\right)$, suggesting that uncontrolled environmental factors (e.g. the order in which replicate fragments were used or the microclimate in fragments) can affect the frequency of lifting. The full generalized linear model (GLM) results are given in Table 1.

\section{Worker-Egg Policing}

The percentage of eggs recovered after 3 days was significantly lower for worker-laid eggs $(51 \pm 13 \%$, range $0-100 \%)$ than for queen-laid eggs (99 $\pm 1 \%$, range $93-100 \%$; logistic regression: scaled $\chi_{1}^{2}=50.27, P<0.0001$; Fig. 3$)$. The recovery of eggs differed significantly between colony fragments (scaled $\chi_{5}^{2}=25.33$, $P=0.0001$ ). In one colony fragment (discriminator workers from Ae160 presented with worker-laid eggs from Ae155) all worker-laid eggs remained after 3 days, while $33-100 \%$ of worker-laid eggs had disappeared in the five remaining trials involving worker-laid eggs.

As is typically the case in Acromyrmex (Dijkstra et al. 2005), workers had stacked the surviving eggs in one or more clumps, each wrapped in a mycelial envelope. The mean \pm SD number of eggs per clump was $7.3 \pm 2.6$ (range 1-15) for queen-laid eggs and $4.1 \pm 2.7$ (range 1-15) for worker-laid eggs, which is not significantly different (Mann-Whitney $U$ test: $Z=-1.29, \mathrm{~N} 1=6, \mathrm{~N} 2=5$, $P=0.247$ ). None of the recovered eggs were shrivelled, damaged or dead, and we never found any eggs or their remains in the arena. The missing eggs cannot have hatched, as the experiment ran for only 3 days, much shorter than the ca. 20 days required for embryonic development in A. echinatior (Dijkstra 2005). These results are consistent with discriminator workers destroying worker-laid reproductive eggs, but not queen-laid eggs. The full GLM results are given in Table 2 .

Table 1

Type III GLM results for the worker-worker policing experiment

\begin{tabular}{|c|c|c|c|c|c|c|}
\hline & $\begin{array}{l}\text { Residual } \\
\text { deviance }\end{array}$ & Cumulative $r^{2}$ & Residual $d f$ & $d f$ & $\chi^{2}$ & $P$ \\
\hline \multicolumn{7}{|l|}{ Lifting } \\
\hline Intercept $^{\dagger}$ & 106.0 & 0 & 97 & 1 & - & - \\
\hline Size of introduced worker ${ }^{\dagger}$ & & & & 1 & 5.48 & 0.019 \\
\hline Colony fragment (i.e. replicate) ${ }^{\dagger}$ & 85.5 & 0.19 & 94 & 2 & 15.76 & 0.000 \\
\hline Reproductive status of introduced worker & 85.0 & 0.20 & 93 & 1 & 0.53 & 0.466 \\
\hline $\begin{array}{l}\text { Reproductive status of introduced worker* } \\
\text { Size of introduced worker }\end{array}$ & 83.5 & 0.21 & 92 & 1 & 1.46 & 0.227 \\
\hline Colony fragment*Worker size & 80.7 & 0.24 & 90 & 2 & 2.83 & 0.242 \\
\hline $\begin{array}{l}\text { Colony fragment*Reproductive status } \\
\text { of introduced worker }\end{array}$ & 80.3 & 0.24 & 88 & 2 & 0.37 & 0.832 \\
\hline \multicolumn{7}{|l|}{ Carrying } \\
\hline Intercept $^{\dagger}$ & 8.8 & 0 & 9 & 1 & - & - \\
\hline Colony fragment (i.e. replicate) & 3.5 & 0.60 & 8 & 2 & 5.31 & 0.070 \\
\hline Size of introduced worker & 2.3 & 0.74 & 6 & 1 & 1.15 & 0.284 \\
\hline Reproductive status of introduced worker & 2.0 & 0.77 & 5 & 1 & 1.44 & 0.229 \\
\hline $\begin{array}{l}\text { Reproductive status of introduced worker* } \\
\text { Size of introduced worker }\end{array}$ & 0.5 & 0.95 & 4 & 1 & 1.55 & 0.213 \\
\hline
\end{tabular}

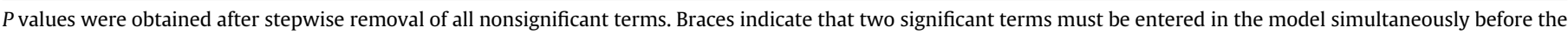
values in the second to fourth columns can be determined.

Terms included in the minimum adequate model. 


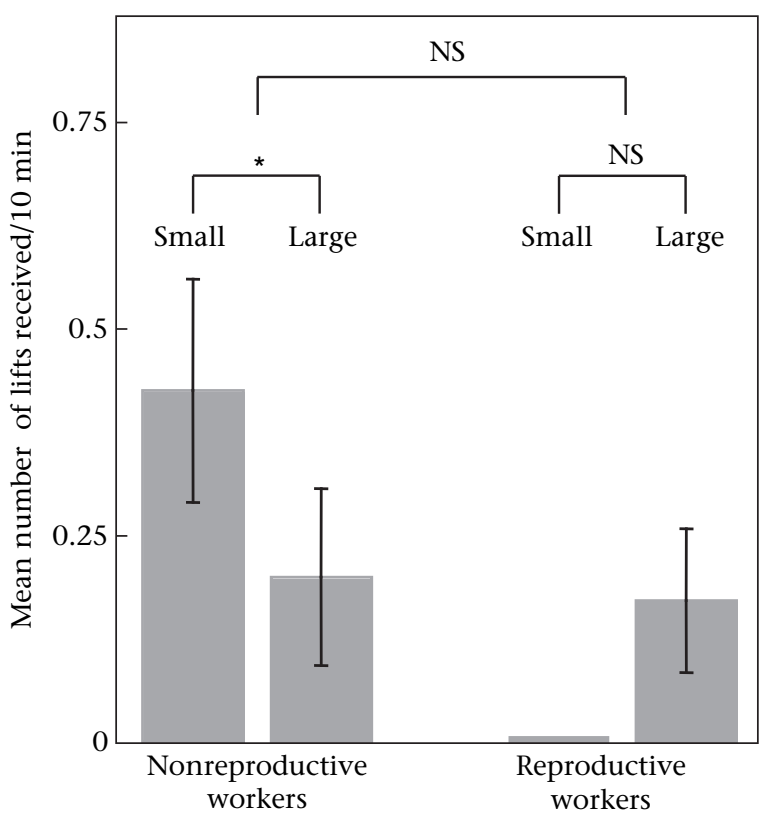

Figure 2. The average frequency of 'lifts' of marked introduced workers (large/small, reproductive/self-restraining) from orphaned nests by related discriminator workers from queenright nests. Only one reproductive small worker was observed. Error bars indicate $95 \%$ confidence limits. ${ }^{*} P<0.05$.

\section{DISCUSSION}

Demonstrating the occurrence of worker policing in fungusgrowing ants (a monophyletic clade that includes the leafcutter ants: Wetterer et al. 1998) is difficult because of the presence of the mutualistic fungus gardens. In the present study we successfully

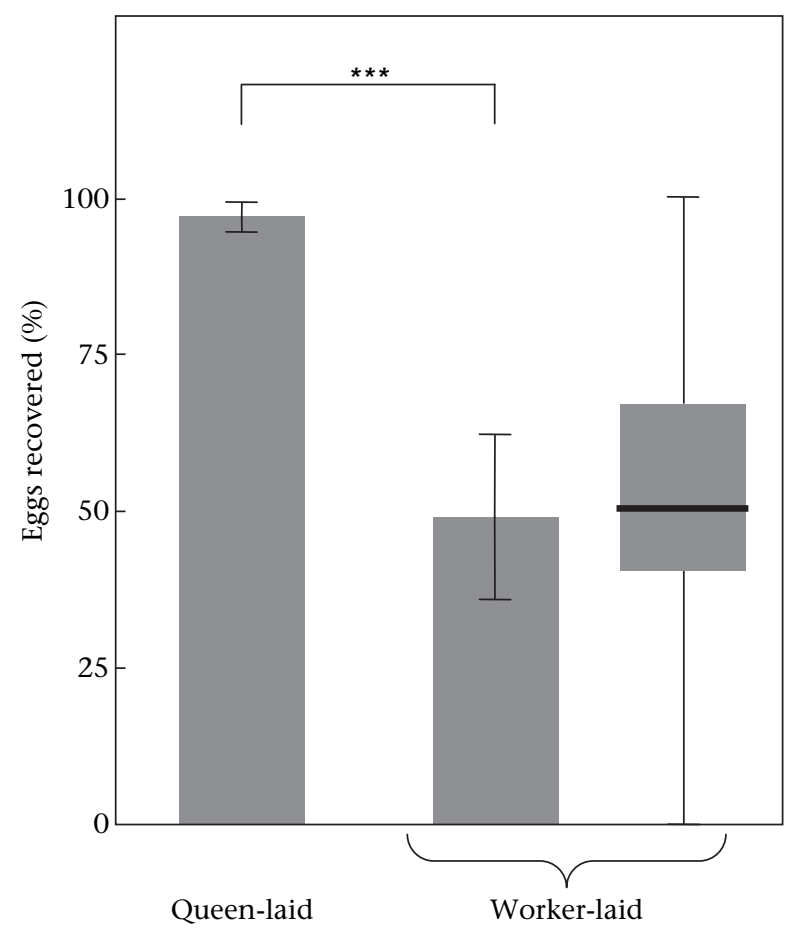

Figure 3. The percentage of introduced queen and worker eggs that were recovered after 3 days. Error bars denote 95\% confidence limits. Each grey bar shows the mean of six trials involving 15 eggs each. ${ }^{* * *} P<0.0001$. For worker-laid eggs, the box plot shows the median, upper and lower quartiles and range. No box plot is shown for queen-laid eggs, as their recovery hardly varied between colony fragments.
Table 2

Type III GLM results for the recovery of introduced eggs in the worker-egg policing experiment, which is taken as a measure of egg survival and thus to reflect the likelihood of egg policing



Chi-square values were corrected for overdispersion ('scaled'). $P$ values were obtained after stepwise removal of all nonsignificant terms. Braces indicate that two significant terms must be entered in the model simultaneously before the values in the second to fourth columns can be determined.

$\ddagger$ Terms included in the minimum adequate model.

developed a dual experimental protocol (adapted from Endler et al. 2004) that could be applied in most fungus-growing ants. Our main finding is that $A$. echinatior workers displayed worker-egg policing, but not worker-worker policing. Below, we speculate on why worker-egg policing might be adaptive for self-restraining A. echinatior workers; we infer that this is probably because of relatedness incentives. This inference would be falsified by demonstrating the existence of worker-egg policing in singly mated genera of fungus-growing ants, using methods from the present study.

\section{Lack of Worker-Worker Policing}

Discriminator workers never fought with introduced workers (i.e. their sisters, but separated from them for 49-84 days) in the present study, yet workers are known to kill unrelated workers that are introduced into similar colony fragments in the laboratory (Lambardi et al. 2004). Except for antennation, the only observed interactions between discriminator and introduced workers were lifting and carrying. These behaviours were not preferentially directed at reproductive workers (Fig. 2), indicating that they are not a form of policing. If lifting and carrying are mildly aggressive behaviours, they probably represent a 'misfiring' of the colony odour recognition system caused by some divergence in odour between the queenright and orphaned nests. Alternatively, lifting up and carrying might represent abortive 'necrophoric' behaviour, by which diseased or dead nestmates are ejected from the nest (see Wilson et al. 1958). The latter interpretation, which would imply that lifting and carrying are mere artefacts of the experimental handling, is supported by our observation that workers that had been handled without gloves were always carried in a similar fashion and deposited in the arena (M. Dirchsen, personal observation). The selective expulsion of reproductive workers by an exapted (i.e. co-opted by evolution: Gould \& Vrba 1982) necrophoric behaviour could be an efficient worker-worker policing mechanism. This is because expelled reproductive workers could work for the colony as foragers or waste disposers, but would no longer have the opportunity to lay eggs, owing to their isolation from the brood and because 'outside duty' workers tend to resorb their ovaries (Dijkstra et al. 2005). This potential mechanism does not appear to be used for policing in A. echinatior, but warrants investigation in other ants.

\section{Worker-Egg Policing does Occur}

On average, $51 \%$ of the worker-laid eggs that had been introduced to the colony fragments were recovered after 3 days, compared to $99 \%$ of queen-laid eggs (grey bars in Fig. 3). The fate of the missing eggs is unknown. We did not find any debris of eggs among the waste in the arena, suggesting that A. echinatior workers completely destroy unwanted eggs, sometimes after temporarily discarding 
them on piles of infrabuccal pellets away from the fungus garden (see Methods). The most likely explanation is that the missing eggs had been cannibalized by discriminator workers, given that leafcutter ant workers are also known to eat morphologically specialized trophic eggs (Dijkstra et al.2005) and occasionally surplus larvae and pupae (Goetsch 1939; Weber 1972; Dijkstra \& Boomsma 2007). However, we cannot rule out that the missing eggs in our experiments had been merely punctured by the discriminator workers, and subsequently overgrown and digested by the fungus. The intensity of policing of worker-laid eggs varied between colony fragments, and one colony fragment did not destroy any of the presented workerlaid eggs (box plot in Fig. 3). In African honeybees, where worker-egg policing normally occurs, nonpolicing colonies are sometimes found (Beekman et al. 2002), and it possible that colony Ae160 in our study was a similar nonpolicing colony. However, we cannot rule out that the lack of worker-egg policing by Ae160 was an artefact of our unnaturally small colony fragments. Our results also indicate that $A$. echinatior workers readily accept eggs laid by unrelated queens, unlike workers in the ant Formica fusca (Helanterä \& Sundström 2007). Our estimate of $49 \%$ policed worker-laid eggs is likely to be an underestimate of the intensity of worker-egg policing in A. echinatior for two reasons: (1) mature colonies contain ca. 100-1000 times more workers than the colony fragments used in the present study, and (2) our experiment ran for only 3 days, whereas worker-laid eggs might be policed at any time during the ca. 20 days needed for embryonic development (Dijkstra 2005).

\section{Colony Efficiency Incentives?}

We have previously estimated (Dijkstra \& Boomsma 2007) that queenright colonies could accommodate a ca. 10-25× increase in the percentage of reproductive workers compared to the current level of ca. $1 \%$ without a detectable decrease in colony productivity $(<2 \%)$, as long as the raising of queen- and worker-derived sexual larvae is seasonally suppressed. This makes it highly unlikely that worker policing is selectively maintained by colony efficiency incentives in A. echinatior. In any case, A. echinatior workers do not show worker-worker policing, which, provided that aggression stimulates reproductive workers to regress their ovaries and adopt self-restraint, is the only known policing mechanism by which workers might immediately increase colony productivity. Because there is no physical connection between workers and the eggs they have laid, worker-egg policing can only promote the evolutionary spread of worker self-restraint indirectly (Wenseleers et al. 2004a, b), without affecting the behaviour of existing reproductive workers.

\section{Sex Ratio Incentives?}

Worker-egg policing helps A. echinatior workers to bias the colony sex ratio further towards virgin queens, but this incentive is minimal for two reasons: (1) the operational population sex allocation ratio in Gamboa, Panama (where the experimental colonies had been collected) is 60\% energy invested in virgin queens and $40 \%$ in males, which is close to the worker optimum for the population sex allocation ratio (58\% invested in virgin queens) and also to the queen's optimum (50\% invested in virgin queens; Dijkstra \& Boomsma 2008); and (2) selection will promote worker-egg policing as a mechanism for increasing virgin queen bias only if the removal of surplus queen and worker sons during the early larval stages is significantly less cost-effective than the removal of exclusively worker sons during the egg stage (Foster \& Ratnieks 2001); our low estimate for the colony-level cost of worker laying (which included the cumulative effect of the presence of early instar worker-derived male larvae: Dijkstra \& Boomsma 2007), suggests that this condition is not necessarily met in A. echinatior.

\section{Preselecting for Viability?}

Nonacs (2006) proposed that worker-egg policing might serve to minimize the waste of colony resources (e.g. brood cells), by removing in advance those eggs that are less likely to hatch in the future. Nonacs's 'preselection for viability' hypothesis assumes that worker-laid eggs are on average less viable than queen-laid eggs, which is the case in many taxa (e.g. Pirk et al. 2004; Helanterä et al. 2006; Khila \& Abouheif 2008). The 'preselection for viability' hypothesis does not predict that only dead eggs get removed (proposed by Pirk et al. 2004 and conclusively refuted by Beekman \& Oldroyd 2005 in honeybees).

We do not know whether $A$. echinatior worker-laid eggs are always as viable as queen-laid eggs. It is likely that 'reproductive constraint' causes at least some A. echinatior worker-laid eggs to die during early embryogenesis, as is the case in other ants (Khila \& Abouheif 2008). We thus cannot rule out that nonviable eggs were overrepresented among the policed eggs in our study. However, many of the introduced worker-laid eggs must have been viable: on average $49 \%$ of introduced eggs were policed, and we exclusively introduced eggs that had been collected from nests that had been orphaned for 14-33 weeks. This time window corresponds to the period after queen loss when most worker sons (ca. $67 \%$ ) that ever get successfully raised in orphaned laboratory colonies of $A$. echinatior originate as eggs (estimated from Figure 2a in Dijkstra \& Boomsma 2007, assuming a development time of 10 weeks from egg to pupation: see Dijkstra 2005). Moreover, eggs are never abundant in orphaned laboratory colonies of $A$. echinatior (M. B. Dijkstra \& J. S. van Zweden, independent personal observations). This implies that worker sons raised in orphaned nests are not rare survivors from a large cohort of mainly nonviable workerlaid eggs. Furthermore, ants never have brood cells (which can be a limiting resource in wasps and bees), so that ant workers would benefit less than bee and wasp workers from preselecting the most viable eggs (see Nonacs 2006). These considerations suggest that the anticipatory removal of eggs that are less likely to be viable is not the main ultimate cause of worker-egg policing in A. echinatior.

\section{Relatedness Benefits?}

After elimination of all alternative explanations, relatedness incentives are left as the most likely ultimate cause of the evolutionary maintenance of worker-egg policing in A. echinatior. Queens of $A$. echinatior are highly multiply mated (Sumner et al. 2004), so that workers can increase their relatedness to the males they raise by up to $47 \%$ if they replace all worker sons $(\bar{r} \pm \mathrm{SE}=0.17 \pm 0.05)$ with queen sons $(\bar{r}=0.25$; see Ratnieks 1988). In theory, surplus worker sons might be removed at any developmental stage, but in reality workers probably need to identify and remove worker sons during the egg stage. This is because hatching and moulting would eliminate any caste-specific cuticular hydrocarbon signature that might have been actively or passively acquired by the egg during its passage through the reproductive tract (Foster \& Ratnieks 2001; Endler et al. 2004, 2005).

\section{Directions for Future Work}

Our inference that $A$. echinatior workers use worker-egg policing to maximize relatedness to the male brood would be falsified if worker-egg policing were to be found in the more basal genera of fungus-growing ants, such as Cyphomyrmex, Trachymyrmex and Sericomyrmex. In these genera, self-restraint is common and worker sons are only produced after queen loss, as is the case in Acromyrmex (Murakami et al. 2000; Villesen et al. 2002; Villesen \& Boomsma, 2003; Dijkstra \& Boomsma 2007, 2008). However, queens of these genera are singly mated, so that workers are more related to worker 
sons $(\bar{r}=0.375)$ than to queen sons $(\bar{r} \leq 0.25)$ and worker-egg policing should not occur. Worker-egg policing is also predicted to occur in the multiply mated Atta leafcutter ants (the sister genus of Acromyrmex), but there worker reproduction is so rare (even after queen loss: Dijkstra et al. 2005; Dijkstra \& Boomsma 2006) that the expression of worker-egg policing might have secondarily become rudimentary. Future studies can test these predictions with the methods developed in the present study, and also measure the proportion of viable worker-laid eggs with the molecular techniques from Khila \& Abouheif (2008).

\section{Acknowledgments}

We thank the Smithsonian Tropical Research Institute and the Autoridad Nacional del Ambiente in Panama for permission to collect and export the colonies, Sylvia Mathiasen, Charlotte Andersen, and Henning Bang Madsen for help in feeding and maintaining the colonies in the laboratory, Danielle Mersch for advice on Fig. 1, Patrizia d'Ettorre for advice on the egg policing experiment, and A. SendovaFranks and two anonymous referees for comments on the manuscript. This work was funded by a Ph.D. fellowship from the University of Copenhagen to M.B.D. and a grant from the Danish National Research Foundation to J.J.B. J.S.v.Z. was supported by the EU Marie Curie Excellence Grant CODICES-EXT-CT-2004-014202 to Patrizia d'Ettorre.

\section{References}

Alves, D. A., Imperatriz-Fonseca, V. L., Francoy, T. M., Santos-Filho, P. S., Nogueira-Neto, P., Billen, J. \& Wenseleers, T. 2009. The queen is dead: long live the workers: intraspecific parasitism by workers in the stingless bee Melipona scutellaris. Molecular Ecology, 18, 4102-4111.

Beekman, M., Good, G., Allsop, M. H., Radloff, S., Pirk, C. W. W. \& Ratnieks, F. L. W. 2002. A non-policing honey bee colony. (Apis mellifera capensis). Naturwissenschaften, 89, 479-482.

Beekman, M. \& Oldroyd, B. P. 2005. Honey bee workers use cues other than egg viability for policing. Biology Letters, 1, 129-132.

Bourke, A. F. G. 1988. Worker reproduction in the higher eusocial Hymenoptera. Quarterly Reviews of Biology, 63, 291-310.

Choe, J. C. 1988. Worker reproduction and social evolution in ants (Hymenoptera: Formicidae). In: Advances in Myrmecology (Ed. by J. C. Trager), pp. 163-187. New York: E.J. Brill.

Cole, B. J. 1986. The social behaviour of Leptothorax allardycei (Hymenoptera, Formicidae): time budgets and the evolution of worker reproduction. Behavioral Ecology and Sociobiology, 18, 253-260.

Currie, C. R. 2001. A community of ants, fungi, and bacteria; a multilateral approach to studying symbiosis. Annual Reviews of Microbiology, 55, 357-380.

D'Ettorre, P., Heinze, J. \& Ratnieks, F. L. W. 2004. Worker policing by egg-eating in the ponerine ant, Pachycondyla inversa. Proceedings of the Royal Society B, 271, 1427-1434.

Dijkstra, M. B. 2005. The regulation of male production in leafcutter ants. Ph.D. thesis, University of Copenhagen.

Dijkstra, M. B. \& Boomsma, J. J. 2006. Are workers of Atta leafcutter ants capable of reproduction? Insectes Sociaux, 53, 136-140.

Dijkstra, M. B. \& Boomsma, J. J. 2007. The economy of worker reproduction in Acromyrmex leafcutter ants. Animal Behaviour, 74, 519-529.

Dijkstra, M. B. \& Boomsma, J. J. 2008. Sex allocation in fungus-growing ants: queen or worker control without symbiont-induced female bias. Oikos, 117, 1892-1906.

Dijkstra, M. B., Nash, D. R. \& Boomsma, J. J. 2005. Self-restraint and sterility in workers of Acromyrmex and Atta leafcutter ants. Insectes Sociaux, 52, 67-76.

Endler, A., Liebig, J., Schmitt, T., Parker, J., Jones, G., Schreier, P. \& Hölldobler, B. 2004. Surface hydrocarbons of queen eggs regulate worker reproduction in a social insect. Proceedings of the National Academy of Sciences, U.S.A., 101, 2945-2950.

Endler, A., Liebig, J. \& Hölldobler, B. 2005. Queen fertility, egg marking and colony size in the ant Camponotus floridanus. Behavioral Ecology and Sociobiology, 59, 490-499.

Foster, K. R. \& Ratnieks, F. L. W. 2000. Facultative worker policing in a wasp. Nature, 401, 692-693.

Foster, K. R. \& Ratnieks, F. L. W. 2001. The effect of sex-allocation biasing on the evolution of worker policing in Hymenopteran societies. American Naturalist, 158, 615-622.

Foster, K. R., Gulliver, J. \& Ratnieks, F. L. W. 2002. Worker policing in the European hornet Vespa crabro. Insectes Sociaux, 49, 41-44.

Gobin, B., Heinze, J., Strätz, M. \& Roces, F. 2003. The energetic cost of reproductive conflicts in the ant Pachycondyla obscuricornis. Journal of Insect Physiology, 49, 747-752.

Goetsch, W. 1939. Die Staaten argentinischer Blattschneider-Ameisen. Zoologica Stuttgart, 35, 1-105

Gould, S. \& Vrba, E. 1982. Exaptation: a missing term in the science of form. Paleobiology, 8, 4-15.

Hammond, R. L. \& Keller, L. 2004. Conflict over male parentage in social insects. PLOS Biology, 2, E248.
Hartmann, A. \& Heinze, J. 2003. Lay eggs, live longer: division of labor and life span in a clonal ant species. Evolution, 57, 2424-2429.

Hartmann, A., Wantia, J., Torres, J. A. \& Heinze, J. 2004. Worker policing without genetic conflicts in a clonal ant. Proceedings of the National Academy of Sciences, U.S.A., 100, 12836-12840.

Helanterä, H. 2007. How to test an inclusive fitness hypothesis: worker reproduction and policing as an example. Oikos, 116, 1782-1788, doi:10.1111| j.2007.0030-1299.16091.x.

Helanterä, H. \& Sundström, L. 2005. Worker reproduction in the ant Formica fusca. Journal of Evolutionary Biology, 18, 162-171.

Helanterä, H. \& Sundström, L. 2007. Worker policing and nest mate recognition in the ant Formica fusca. Behavioral Ecology and Sociobiology, 61, 1143-1149.

Helanterä, H., Tofilski, A., Wenseleers, T. \& Ratnieks, F. L. W. 2006. Worker policing in the common wasp Vespula vulgaris is not aimed at improving colony hygiene. Insectes Sociaux, 53, 339-402.

Jeffery, W. R. 2005. Adaptive evolution of eye degeneration in the Mexican blind cavefish. Journal of Heredity, 96, 185-196.

Kellner, K., Trindl, A., Heinze, J. \& d'Ettorre, P. 2007. Polygyny and polyandry in small ant societies. Molecular Ecology, 16, 2363-2369.

Khila, A. \& Abouheif, E. 2008. Reproductive constraint is a developmental mechanism that maintains social harmony in advanced ant societies. Proceedings of the National Academy of Sciences, U.S.A., 105, 17884-17889.

Lambardi, D., Chegia, B., Turillazzi, S. \& Boomsma, J.J. 2004. Diet-induced aggression among colonies of the leafcutter ant Acromyrmex echinatior. Redia, 87, 219-222.

Little, A. E. F., Murakami, T., Mueller, U. G. M. \& Currie, C. R. 2003. The infrabuccal pellet piles of fungus-growing ants. Naturwissenschaften, 90, 558-562.

Murakami, T., Higashi, S. \& Windsor, D. 2000. Mating frequency, colony size, polyethism and sex ratio in fungus-growing ants (Attini). Behavioral Ecology and Sociobiology, 48, 276-284.

Nonacs, P. 2006. Nepotism and brood reliability in the suppression of worker reproduction in the eusocial Hymenoptera. Biology Letters, 22, 577-579.

Pamilo, P. 1991. Evolution of colony characteristics in social insects. II. Number of reproductive individuals. American Naturalist, 138, 412-433.

Pirk, C. W. W., Neumann, P. \& Ratnieks, F. L. W. 2003. Cape honeybees, Apis mellifera capensis, police worker-laid eggs despite the absence of relatedness benefits. Behavioral Ecology and Sociobiology, 14, 347-352.

Pirk, C. W. W., Neumann, P., Hepburn, R., Moritz, R. F. A. \& Tautz, J. 2004. Egg viability and worker policing in honey bees. Proceedings of the National Academy of Sciences, U.S.A., 101, 8649-8651.

Protas, M., Conrad, M., Gross, J. B., Tabin, C. \& Borowsky, R. 2007. Regressive evolution in the Mexican cave tetra, Astyanax mexicanus. Current Biology, 17, 452-454.

Ratnieks, F. L. W. 1988. Reproductive harmony via mutual policing by workers in eusocial Hymenoptera. American Naturalist, 132, 217-236.

Ratnieks, F. L. W. \& Visscher, P. K. 1989. Worker policing in the honeybee. Nature, 342, 796-797.

Ratnieks, F. L. W. \& Wenseleers, T. 2008. Altruism in insect societies and beyond voluntary or enforced? Trends in Ecology \& Evolution, 23, 45-52.

Ratnieks, F. L. W., Foster, K. R. \& Wenseleers, T. 2006. Conflict resolution in insect societies. Annual Review of Entomology, 51, 581-608.

Saigo, T. \& Tsuchida, K. 2004. Queen and worker policing in monogynous and monandrous colonies of a primitively eusocial wasp. Biology Letters, 6, S509-S512.

Stroeymeyt, N., Brunner, E. \& Heinze, J. 2007. 'Selfish worker policing' controls reproduction in a Temnothorax ant. Behavioral Ecology and Sociobiology, 61, 1449-1457.

Sumner, S., Hughes, W. O. H., Pedersen, J. S. \& Boomsma, J. J. 2004. Ant parasite queens revert to mating singly. Nature, 428, 35-36.

Tóth, E., Queller, D. C., Dollin, A. \& Strassmann, J. E. 2004. Conflict over male parentage in stingless bees. Insectes Sociaux, 51, 1-11.

Villesen, P. \& Boomsma, J. J. 2003. Patterns of male parentage in the fungusgrowing ants. Behavioral Ecology and Sociobiology, 53, 246-253.

Villesen, P., Murakami, T., Schultz, T. R. \& Boomsma, J. J. 2002. Identifying the transition between single and multiple mating of queens in fungus-growing ants. Proceedings of the Royal Society B, 269, 1541-1548.

Weber, N. A. 1972. Gardening Ants, the Attines. Philadelphia: American Philosophical Society.

Wenseleers, T. \& Ratnieks, F. L. W. 2006a. Comparative analysis of worker policing and reproduction in eusocial Hymenoptera supports relatedness theory. American Naturalist, 168, E163-E179.

Wenseleers, T. \& Ratnieks, F. L. W. 2006b. Enforced altruism in insect societies Nature, 444, 50

Wenseleers, T., Helanterä, H., Hart, A. \& Ratnieks, F. L. W. 2004a. Worker reproduction and policing in insect societies: an ESS analysis. Journal of Evolutionary Biology, 17, 1035-1047.

Wenseleers, T., Hart, A. G. \& Ratnieks, F. L. W. 2004b. When resistance is useless: policing and the evolution of reproductive acquiescence in insect societies. American Naturalist, 164, E154-E167.

Wetterer, J. K., Schultz, T. R. \& Meier, R. 1998. Phylogeny of fungus-growing ants (tribe Attini) based on mtDNA sequence and morphology. Molecular Phylogenetics and Evolution, 9, 42-47.

Wilson, E. O., Durlach, N. I. \& Roth, L. M. 1958. Chemical releasers of necrophoric behaviour in ants. Psyche, 65, 108-114.

Woyciechowski, M. \& Łomnicki, A. 1987. Mutiple mating of queens and the sterility of workers among eusocial Hymenoptera. Journal of Theoretical Biology, 128, 317-327.

van Zweden, J. S., Fürst, M. A., Heinze, J. \& D'Ettorre, P. 2007. Specialization in policing behaviour among workers in the ant Pachycondyla inversa. Proceedings of the Royal Society B, 274, 1421-1428. 


\section{APPENDIX}

Table A1

Composition of reproductive colonies of $A$. echinatior used in this study

\begin{tabular}{|c|c|c|c|c|c|}
\hline $\begin{array}{l}\text { Colony identity } \\
\text { (exclusively reproductive } \\
\text { colonies with functional } \\
\text { mother queen }(\mathrm{s}) \text { ) }\end{array}$ & $\begin{array}{l}\text { Total fungus garden } \\
\text { volume (rounded off to } \\
\text { the nearest litre) }\end{array}$ & $\begin{array}{l}\text { Total males raised to } \\
\text { adulthood throughout } \\
\text { reproductive season }\end{array}$ & $\begin{array}{l}\text { Estimated total number } \\
\text { of workers in colony, } \\
\text { irrespective of worker } \\
\text { size (rounded off to the } \\
\text { nearest } 1000 \text { ) }\end{array}$ & $\begin{array}{l}\text { Assuming } 1 \% \text { reproductive } \\
\text { workers present in each } \\
\text { queenright colony, how many } \\
\text { reproductive workers will there } \\
\text { be in the colony during the } \\
\text { reproductive season? } \\
\text { (rounded off to the nearest } 10 \text { ) }\end{array}$ & $\begin{array}{l}\text { Assuming one viable } \\
\text { reproductive egg laid per } \\
\text { reproductive worker, } \\
\text { what's the percentage of } \\
\text { all males that could be } \\
\text { produced by workers? } \\
\text { (not allowed to be }>100 \% \text { ) }\end{array}$ \\
\hline Ae-052 & 1 & 0 & 3000 & 30 & 100 \\
\hline Ae-102 & 3 & 25 & 10000 & 100 & 100 \\
\hline Ae-106 & 3 & 161 & 10000 & 100 & 62 \\
\hline Ae-109 & 2 & 155 & 7000 & 70 & 45 \\
\hline Ae-111 & 2 & 26 & 7000 & 70 & 100 \\
\hline Ae-112 & 3 & 946 & 10000 & 100 & 11 \\
\hline Ae-125 & 3 & 664 & 10000 & 100 & 15 \\
\hline Ae-126 & $\leq 0.25$ & 5 & $\leq 500$ & $\leq 5$ & $\leq 83$ \\
\hline Ae-127 & 3 & 0 & 10000 & 100 & 100 \\
\hline Ae-129 & 12 & 693 & 40000 & 400 & 58 \\
\hline Ae-134 & 2 & 183 & 7000 & 70 & 38 \\
\hline Ae-135 & 3 & 362 & 10000 & 100 & 28 \\
\hline Ae-136 & 1 & 127 & 3000 & 30 & 23 \\
\hline Ae-144 & 2 & 8 & 7000 & 70 & 100 \\
\hline Ae-151 & 2 & 80 & 7000 & 70 & 86 \\
\hline Ae-154 & 1 & 0 & 3000 & 30 & 100 \\
\hline Ae-155 & $\leq 0.25$ & 0 & $\leq 500$ & $\leq 5$ & $\leq 100$ \\
\hline Ae-158 & 2 & 493 & $\overline{7} 000$ & 70 & 14 \\
\hline Ae-162 & 2 & 179 & 7000 & 70 & 39 \\
\hline Ae-167 & $\leq 0.25$ & 112 & $\leq 500$ & $\leq 5$ & $\leq 4$ \\
\hline Ae-168 & 2 & 152 & $\overline{7} 000$ & $\overline{70}$ & 46 \\
\hline Ae-171 & 1 & 296 & 3000 & 30 & 10 \\
\hline Ae-172 & 2 & 12 & 7000 & 70 & 100 \\
\hline Ae-175 & 1 & 58 & 3000 & 30 & 51 \\
\hline Ae-176 & $\leq 0.25$ & 8 & $\leq 500$ & $\leq 5$ & $\leq 56$ \\
\hline Ae-177 & $\leq 0.25$ & 1 & $\leq 500$ & $\leq 5$ & $\leq 100$ \\
\hline Ae-178 & 6 & 17 & 20000 & 200 & 100 \\
\hline Ae-185 & 2 & 175 & 7000 & 70 & 40 \\
\hline Ae-186 & $\leq 0.25$ & 8 & $\leq 500$ & $\leq 5$ & $\leq 56$ \\
\hline Ae-187 & 1 & 380 & 3000 & 30 & 8 \\
\hline Ae-189 & 1 & 70 & 3000 & 30 & 42 \\
\hline Ae-190 & 3 & 191 & 10000 & 100 & 52 \\
\hline Ae-207 & 2 & 1 & 7000 & 70 & 100 \\
\hline Ae-208 & 1 & 41 & 3000 & 30 & 71 \\
\hline Ae-209 & 3 & 1 & 10000 & 100 & 100 \\
\hline Ae-211 & 2 & 699 & 7000 & 70 & 10 \\
\hline Ae-214 & 1 & 38 & 3000 & 30 & 77 \\
\hline Ae-216 & 1 & 120 & 3000 & 30 & 25 \\
\hline Ae-217 & $\leq 0.25$ & 106 & $\leq 500$ & $\leq 5$ & $\leq 5$ \\
\hline Ae-221 & $\leq 0.25$ & 1 & $\leq 500$ & $\leq 5$ & $\leq 100$ \\
\hline Ae- 250 & $\leq 0.25$ & 58 & $\leq 500$ & $\leq 5$ & $\leq 8$ \\
\hline Ae-257 & 2 & 148 & 7000 & 70 & 47 \\
\hline Ae-259 & 3 & 319 & 10000 & 100 & 31 \\
\hline Ae-269 & 2 & 49 & 7000 & 70 & 100 \\
\hline \multirow[t]{8}{*}{ Ae-270 } & 1 & 0 & 3000 & 30 & 100 \\
\hline & & & & Mean & $59 \%$ \\
\hline & & & & $N$ & 45 colonies \\
\hline & & & & SD & $36 \%$ \\
\hline & & & & Minimum & $4 \%$ \\
\hline & & & & Maximum & $100 \%$ \\
\hline & & & & SE & $5 \%$ \\
\hline & & & & Median & $56 \%$ \\
\hline
\end{tabular}

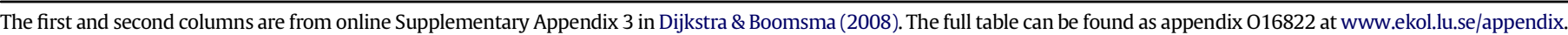

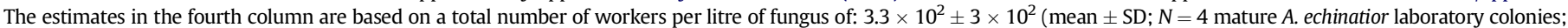
M. Poulsen, unpublished data). 